\title{
Geochemical Behavior of Heavy Metals During Treatment by Phosphoric Fertilizer at a Dumping Site in Kabwe, Zambia
}

\author{
H. Kamegamori ${ }^{1(凶)}$, K. Lawrence ${ }^{1}$, T. Sato ${ }^{2}$, and T. Otake ${ }^{2}$ \\ ${ }^{1}$ Graduate School of Engineering, Hokkaido University, Sapporo, Japan \\ skj-9mm@eis. hokudai.ac.jp \\ 2 Faculty of Engineering, Hokkaido University, Sapporo, Japan
}

\begin{abstract}
Kabwe area in Zambia has been affected by heavy metal contaminations which derived from past mining activities. Particularly, $\mathrm{Pb}$ is one of the most concerned elements for human health in Kabwe. In this context, treatment by phosphoric fertilizer was conducted to reduce $\mathrm{Pb}$ solubility in soil and slag, limiting their bioavailability. Because leach plant residue in Kabwe contains metal sulfate minerals with high solubility, concentration of heavy metals in groundwater is high. We clarified the geochemical behavior of heavy metals $(\mathrm{Pb}, \mathrm{Cd}, \mathrm{Zn}$ and $\mathrm{Cu})$ after the addition of phosphoric fertilizer (Triple Super Phosphate: TSP) in column experiment. Immobilization of $\mathrm{Pb}$ and $\mathrm{Cd}$ lowers concentration of the metals in ground below WHO environmental standard.
\end{abstract}

Keywords: Insolubilization - Soil amendments - Heavy metal contamination • Phosphate mineral $\cdot$ Mine waste

\section{Introduction}

Kabwe town is the worst polluted place in Africa due to mining and smelting of $\mathrm{Pb}$ and $\mathrm{Zn}$ ores. Orthophosphate has been receiving a lot of attention as stabilization agent for heavy metals, In order to reduce dispersion and mobility of $\mathrm{Pb}$ metal from the slag, we suggests treatment by adding phosphoric fertilizer (Triple super phosphate: TSP) which is effective and locally available.

\section{Methods and Approaches}

We conducted a series of column experiments in $50 \mathrm{ml}$ of syringe tubes, simulating treatment for stacked slags at a dumping site in Kabwe. The syringes were filled with slags obtained from Kabwe site with $10 \mathrm{~g}$ of TSP on the top of slag sample. $6 \mathrm{~mL}$ of rain water obtained from the site was added every day, which is consistent with average daily precipitation rate. Infiltrated water was collected at the bottom of syringe and analyzed by ICP-AES and ICP-MS. After the column experiments, the slag samples in the column also investigated to understand geochemical processes occurred during the experiments by SEM/EDS. 


\section{Results and Discussion}

We confirm the reduction in $\mathrm{Pb}$ and $\mathrm{Cd}$ concentrations in the eluents. Remarkably, the reduction for $\mathrm{Pb}$ concentration is $96 \%$. In the infiltrated slags simultaneously, we observe the alteration from $\mathrm{PbSO}_{4}$ to $(\mathrm{Pb}, \mathrm{Ca})_{5}\left(\mathrm{PO}_{4}\right)_{3} \mathrm{Cl}$ (Fig. 1), which effects to reduce the mobility of $\mathrm{Pb}$. In contrast, elution of $\mathrm{Zn}$ and $\mathrm{Cu}$ from the slags are promoted by the presence of TSP. This is due to lowering $\mathrm{pH}$ by TSP, desorbed $\mathrm{Zn}$ and $\mathrm{Cu}$ from amorphous and crystalline iron hydroxides. It suggests to supply orthophosphate at neutral $\mathrm{pH}$ range is effective for immobilization of heavy metals in slags.

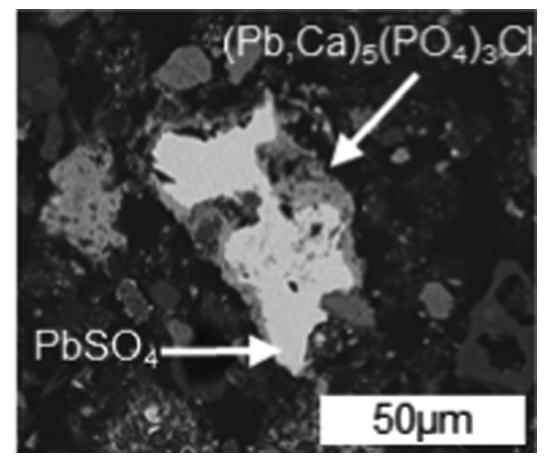

Fig. 1. The alteration from anglesite to pyromorphite

\section{Conclusions}

We confirmed the behavior of some heavy metals applied TSP in column scale. From the results, TSP could immobilize $\mathrm{Pb}$ and $\mathrm{Cd}$, however, it promoted elution of $\mathrm{Zn}$ and $\mathrm{Cu}$ due to soil acidification. This suggests applying TSP with dolomite to the slag could be a better remediation method.

Acknowledgements. This study is supported by International Collaborative Research Program (SATREPS): Visualization of Impact of Chronic/Latent Chemical Hazard and Geo-Ecological Remediation in Zambia. I'm deeply grateful to Dr. Kasama who taught me how to use SEM/EDS in Center for Electron Nanoscopy, Denmark Technical University.

Open Access This chapter is licensed under the terms of the Creative Commons Attribution 4.0 International License (http://creativecommons.org/licenses/by/4.0/), which permits use, sharing, adaptation, distribution and reproduction in any medium or format, as long as you give appropriate credit to the original author(s) and the source, provide a link to the Creative Commons license and indicate if changes were made.

The images or other third party material in this chapter are included in the chapter's Creative Commons license, unless indicated otherwise in a credit line to the material. If material is not included in the chapter's Creative Commons license and your intended use is not permitted by statutory regulation or exceeds the permitted use, you will need to obtain permission directly from the copyright holder.

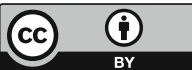

